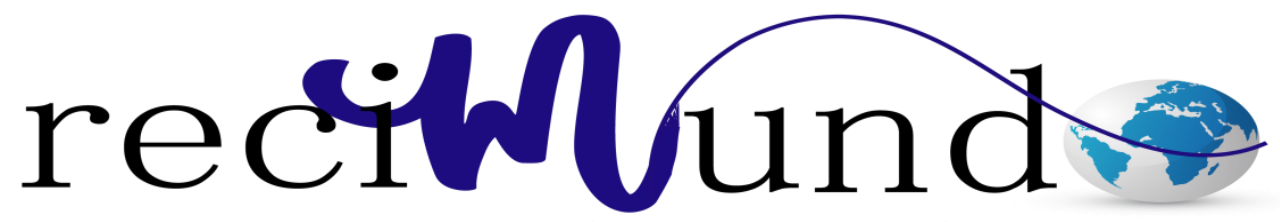

Revista Cientifica Mundo de la Investigación y el Conocimiento

Irma Parrales Pincay ${ }^{\text {a }}$, Cristobal Franco Quinde ${ }^{\text {b; }}$ William Lino Villacreses ${ }^{c}$; María Chávez Rivadeneira ${ }^{\mathrm{d}}$

Especies de Cándidas como agentes causales de micosis vaginal en mujeres sexualmente activas

Revista Científica Mundo de la Investigación y el Conocimiento. Vol. 2 núm., 1, febrero, ISSN: 2588-073X, 2018, pp. 283-301

DOI: $10.26820 /$ recimundo/2.1.2018.283-301

Editorial Saberes del Conocimiento

Recibido: 05/12/2017

Aceptado: 10/02/2018

a. Universidad Estatal del Sur de Manabí; irma.parrales@unesum.edu.ec

b. Universidad Estatal del Sur de Manabí; cristobal.franco@unesum.edu.ec

c. Universidad Estatal del Sur de Manabí; william.lino@unesum.edu.ec

d. Universidad Estatal del Sur de Manabí; maite-50@ hotmail.com 


\section{Especies de Cándidas como agentes causales de micosis vaginal en mujeres sexualmente activas}

Vol. 2, núm. 1., (2018)

Irma Parrales Pincay; Cristobal Franco Quinde; William Lino Villacreses; María Chávez Rivadeneira

\section{RESUMEN}

La micosis vaginal es una patología que afecta a un gran número de mujeres sexualmente activas en nuestro país, según datos del MSP 8 de cada 10 mujeres pasarán por un cuadro de micosis vaginal en algún momento de su vida. El objetivo principal de este trabajo de investigación fue determinar especies de cándidas como agentes causales de micosis vaginal en mujeres sexualmente activas atendidas en CS. Charapotó del Cantón Sucre. Se utilizó una metodología descriptiva, analítica y estadística para desarrollar y ejecutar dicha investigación, se planteó una hipótesis y el presente estudio se sustentó con bases científicas. Se aplicó la técnica de encuesta logrando establecer los principales factores de riesgo. Se realizaron exámenes clínicos de muestras de secreción vaginal las cuales fueron cultivadas en dos medios denominados Agar Sabouraud y Chromagar. El estudio contó con la participación de 30 mujeres sexualmente activas de las cuales el 80,00\% presentó micosis vaginal por especies de cándida y un 20,00\% no padecía de esta patología. Como medida de prevención se ejecutó un plan de capacitación destinado a mejorar la salud femenina. En conclusión el 80,00\% de los casos positivos de micosis vaginal tuvieron como factor predisponente el uso de ropa íntima inadecuada de las mujeres sexualmente activas atendidas en el Centro de Salud Charapotó del Cantón Sucre.

Palabras clave: Secreción vaginal, especies de cándidas, factores de riesgo, micosis vaginal, medios de cultivos. 


\title{
Especies de Cándidas como agentes causales de micosis vaginal en mujeres
}

sexualmente activas

Vol. 2, núm. 1., (2018)

Irma Parrales Pincay; Cristobal Franco Quinde; William Lino Villacreses; María Chávez

Rivadeneira

\begin{abstract}
The vaginal mycosis is a pathology that affects a large number of sexually active women in our country, according to data from the MSP 8 out of 10 women will go through a picture of vaginal mycosis at some point in their life. The main objective of this research work was to determine candid species as causative agents of vaginal mycosis in sexually active women treated at CS. Charapotó del Cantón Sucre. A descriptive, analytical and statistical methodology was used to develop and execute said research, a hypothesis was proposed and the present study was based on scientific bases. The survey technique was applied, establishing the main risk factors. Clinical examinations of samples of vaginal secretion were carried out which were cultivated in two media called Agar Sabouraud and Chromagar. The study counted with the participation of 30 sexually active women of which $80.00 \%$ presented vaginal mycosis for candida species and $20.00 \%$ did not suffer from this pathology. As a preventive measure, a training plan was implemented to improve women's health. In conclusion, $80.00 \%$ of the positive cases of vaginal mycosis had as a predisposing factor the use of inappropriate intimate clothing of the sexually active women attended at the Charapotó Health Center of the Cantón Sucre.
\end{abstract}

Keywords: Vaginal secretion, candid species, risk factors, vaginal mycosis, culture media. 


\section{Especies de Cándidas como agentes causales de micosis vaginal en mujeres sexualmente activas}

Vol. 2, núm. 1., (2018)

Irma Parrales Pincay; Cristobal Franco Quinde; William Lino Villacreses; María Chávez Rivadeneira

\section{Introducción.}

La presente investigación hizo referencia a especies de cándidas como agentes causales de micosis vaginal en mujeres sexualmente activas atendidas en Centro de Salud Charapotó del Cantón Sucre, cuyos objetivos fueron determinar los factores de riesgo que causan una infección en la vagina, identificar las especies más comunes de este microorganismo analizando muestras de secreción vaginal mediante Agar Sabouraud, Agar Chromagar y diseñar un plan de capacitación sobre la prevención de este problema de salud. $(1,2,3)$

La Organización Mundial de la Salud, establece que las infecciones vaginales por hongos del género cándidas prevalecen en 14 países representativos de 4 Regiones (Europa, el Mediterráneo Oriental, el Asia Sudoriental y el Pacífico Occidental) con más de 1,4 millones de casos de infecciones al año. Un $26 \%$ de las mujeres embarazadas tienen presencia de cándida sin presentar síntomas mientras que un 30\% manifiestan síntomas que causan malestar en la zona genital y riesgo durante el embarazo. $(4,5)$

En el Ecuador según datos del Ministerio de Salud Pública, se registraron un total de 7.993 casos de candidiasis no especificadas; a nivel de la Provincia de Manabí se dieron un total de 9.587 casos de candidiasis de vulva y vagina, mientras que en el Cantón Sucre se reportaron 520 casos de candidiasis vaginal de los cuales 133, correspondían a pacientes que acudían de la localidad de Charapotó. (6)

La Cándida es un hongo que se encuentra como parte normal de la flora vaginal, sin embargo está puede sufrir alteraciones por causa de varios factores. Es un problema de salud que 


\section{Especies de Cándidas como agentes causales de micosis vaginal en mujeres}

sexualmente activas

Vol. 2, núm. 1., (2018)

Irma Parrales Pincay; Cristobal Franco Quinde; William Lino Villacreses; María Chávez

Rivadeneira

$\overline{\text { afecta a un gran número de personas de sexo femenino que han iniciado su vida sexual o están en }}$ un periodo de embarazo. Las especies de hongos o levaduras del género Cándida más comunes son la Cándida albicans, Cándida tropicalis, Cándida krusei. (7)

Los cambios hormonales, uso de métodos anticonceptivos intrauterinos, mal aseo de la zona genital, sistema inmunológico debilitado, la diabetes y el embarazo son los factores de riesgo más comunes, para la proliferación de cándidas y provocar una micosis vaginal que puede presentarse de forma asintomática como sintomáticamente en las mujeres sexualmente activas. Cualquiera que fuera la causa de la misma, esta provoca la emisión de flujo vaginal blanco, prurito, relaciones sexuales dolorosas y en caso de mujeres embarazadas puede causar abortos, si esta patología no es diagnosticada a tiempo. (8)

La micosis vaginal es una inflamación de la vagina provocada por varias especies de hongos o levaduras del género Cándida. Generalmente la especie de mayor prevalencia en los episodios de micosis es la Cándida albicans que representa el $90 \%$ de los casos, mientras que el porcentaje restante corresponde a otras especies como la Cándida tropicalis y la Cándida krusei. La mayoría de las mujeres sexualmente activas pasarán por un episodio de micosis vaginal en algún momento de su vida. (9)

Tomando en consideración la información en base a las variables de esta investigación se planteó que el $80 \%$ de las mujeres sexualmente activas que acuden al Centro de Salud Charapotó con ardor, presencia de flujo vaginal, picor e inflamación en la vulva es debido a la micosis vaginal por especies de Cándidas, manejándose este dato como hipótesis en el presente trabajo. 


\section{Especies de Cándidas como agentes causales de micosis vaginal en mujeres sexualmente activas}

Vol. 2, núm. 1., (2018)

Irma Parrales Pincay; Cristobal Franco Quinde; William Lino Villacreses; María Chávez Rivadeneira

La metodología empleada en esta investigación fue descriptivo, para evaluar los factores de riesgo causantes de la problemática estudiada, analítico con ayuda de pruebas de laboratorio para identificar la especie de Cándida causante de micosis vaginal y estadístico para cuantificar los datos obtenidos y establecer la especie que predomina. Los resultados se obtuvieron mediante el uso de encuestas para conocer los factores de riesgo asociados a la micosis vaginal y la identificación de especies de Cándidas se lo realizó mediante la toma y siembra de muestras de secreción vaginal en Agar Sabouraud y Chromagar.

Esta investigación fue de relevancia científica, ya que estuvo orientada en el campo de la salud para contribuir así con un diagnóstico oportuno de la micosis vaginal causada por especies de Cándidas y por ende capacitar a las mujeres sexualmente activas que acuden al Centro de Salud Charapotó del Cantón Sucre, para que tengan conocimiento acerca de los múltiples factores de riesgo que desencadenan en este problema de salud.

\section{Importancia del Problema}

Este trabajo se enfocó en el estudio de las especies de Cándidas como agentes causales de micosis vaginal en mujeres sexualmente activas atendidas en Centro de Salud Charapotó del Cantón Sucre, considerando que en la actualidad esta afección causada por dichos microorganismo es una de las principales causas de atención primaria de salud.

Se plantearon objetivos claros y precisos que llevaron al análisis de esta problemática; en la cual también se contó con métodos y técnicas necesarias para el estudio a realizar. Esta investigación fue de vital importancia, ya que fue un aporte al campo de la salud y por ende a la 


\section{Especies de Cándidas como agentes causales de micosis vaginal en mujeres}

sexualmente activas

Vol. 2, núm. 1., (2018)

Irma Parrales Pincay; Cristobal Franco Quinde; William Lino Villacreses; María Chávez

Rivadeneira

población en estudio, teniendo en cuenta que la micosis vaginal causada por especies de Cándidas es muy común y habitual en nuestro medio, dando a conocer que de cada diez mujeres ocho presentarán un episodio de esta patología en algún momento de su vida.

Por lo consiguiente, las beneficiadas de esta investigación fueron las mujeres sexualmente activas atendidas en el Centro de Salud Charapotó del Cantón Sucre que por diversos factores como el económico, la falta de recursos materiales en el establecimiento de salud de la localidad no pueden realizarse un cultivo de secreción vaginal.

A demás se pretendió lograr un impacto positivo en la salud de las usuarias del Centro de Salud Charapotó, la factibilidad de esta investigación es total, debido a que se contó con los recursos económicos, bibliográficos, técnicos, predisposición del establecimiento de salud y de la población de mujeres sexualmente activas que acuden al Centro de Salud.

El investigador buscó brindar beneficios sociales a la comunidad en este caso a las mujeres sexualmente activas acuden al Centro de Salud Charapotó, identificando los factores de riesgo y las especies de Cándidas causantes de micosis vaginal mediante el análisis de sus muestras de secreción vaginal; además de diseñar un plan de capacitación sobre la prevención de la patología antes mencionada y mejorar sus condiciones de vida.

\section{Metodología.}

En cuanto al proceso metodológico se consideró lo siguiente: 


\section{Especies de Cándidas como agentes causales de micosis vaginal en mujeres sexualmente activas}

Vol. 2, núm. 1., (2018)

Irma Parrales Pincay; Cristobal Franco Quinde; William Lino Villacreses; María Chávez Rivadeneira

La población estudiada en esta investigación lo constituyeron las mujeres sexualmente activas atendidas en el Centro de Salud Charapotó del Cantón Sucre.

Muestra la representaron las mujeres sexualmente activas que acuden al Centro de Salud Charapotó del Cantón Sucre, optando un muestreo no probabilístico voluntario; el cual se realizó mediante criterios de inclusión y exclusión dando un total de 30 muestras.

\section{Criterios de Inclusión:}

- Mujeres sexualmente activas atendidas en Centro de Salud Charapotó del Cantón Sucre.

- Mujeres sexualmente activas que den su consentimiento informado y que contesten las preguntas de la encuesta.

- Mujeres sexualmente activas que cumplan con los requerimientos previos para la toma de muestra.

\section{Criterios de Exclusión}

- Mujeres sexualmente activas que no son atendidas en Centro de Salud Charapotó del Cantón Sucre.

- Mujeres sexualmente activas que no den su consentimiento informado y que no contesten las preguntas de la encuesta.

- Mujeres sexualmente activas que no cumplan con los requerimientos previos para la toma de muestra. 


\section{Especies de Cándidas como agentes causales de micosis vaginal en mujeres}

sexualmente activas

Vol. 2, núm. 1., (2018)

Irma Parrales Pincay; Cristobal Franco Quinde; William Lino Villacreses; María Chávez

Rivadeneira

Entre los métodos utilizados para llevar a cabo la investigación están los siguientes:

Método Descriptivo: Consistió en obtener información científica bibliográfica y documental que aportó de forma teórica a la investigación propuesta con el tema: Especies de cándidas como agentes causales de micosis vaginal en mujeres sexualmente activas atendidas en Centro de Salud Charapotó del Cantón Sucre, donde se aplicaron conceptos y preposiciones lógicas que constituyeron el marco contextual de la investigación.

Método Analítico: Mediante la experimentación y el conocimiento científico práctico de pruebas de laboratorio se logró obtener el resultado a través de un medio para el aislamiento de las especies de cándidas denominado Agar Sabouraud, Agar Chromagar, también se analizaron los resultados de las encuestas las cuales se relacionan con los factores de riesgo que desencadenan una posible micosis vaginal.

Método Estadístico: Mediante el proceso de obtención de información de las encuestas y los resultados de la experimentación, se analizaron e interpretaron las características proyectadas en la investigación, y así tener una visión más amplia acerca de la realidad del sector estudiado.

\section{Técnicas e Instrumentos que facilitaron el proceso investigativo}

Las técnicas que se utilizaron para la recolección e información del trabajo de investigación fueron:

- Encuesta.

- Registro de Muestras. 


\section{Especies de Cándidas como agentes causales de micosis vaginal en mujeres sexualmente activas}

Vol. 2, núm. 1., (2018)

Irma Parrales Pincay; Cristobal Franco Quinde; William Lino Villacreses; María Chávez Rivadeneira

- Pruebas Micológicas de Laboratorio.

- Instrumentos

Para el presente trabajo se utilizaron: cuadernos de notas, base de datos, cámara fotográfica y materiales de laboratorio clínico. Todos estos instrumentos nos permitieron recaudar la información necesaria, para el desarrollo del proyecto de investigación acorde al tema propuesto.

\section{Resultados.}

El presente estudio sobre Especies de cándidas como agentes causales de micosis vaginal en mujeres sexualmente activas atendidas en Centro de Salud Charapotó, se fundamentó en la metodología de la aplicación de encuestas sobre los factores de riesgo y la técnica de diagnóstico en cultivo de muestra de secreción vaginal en Agar Sabouraud y Chromagar, obteniendo el siguiente análisis. 
Especies de Cándidas como agentes causales de micosis vaginal en mujeres sexualmente activas Vol. 2, núm. 1., (2018) Irma Parrales Pincay; Cristobal Franco Quinde; William Lino Villacreses; María Chávez Rivadeneira

¿Usted ha padecido de micosis vaginal o infección en la vagina?

\section{Cuatro y grafico \#1}

\begin{tabular}{l|lc}
\multicolumn{1}{l}{ Variable } & Prevalencia & Porcentajes \\
\hline SI & 24 & $80 \%$ \\
NO & 6 & $20 \%$ \\
TOTALES & 30 & $100 \%$ \\
\multicolumn{2}{l}{ Fuente: } & \multicolumn{2}{l}{ Mujeres atendidas en CS Charapoto }
\end{tabular}

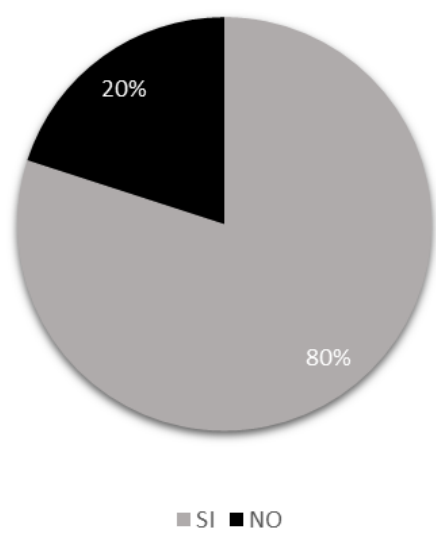

En el primer ítem relacionado a si habían padecido de micosis vaginal o infección en la vagina, de un total de 30 mujeres encuestadas, el $80,00 \%$ correspondiente a 24 mujeres manifestaron que sí, mientras que el 20,00\% correspondiente a 6 mujeres se pronunciaron con el no. 


\section{Especies de Cándidas como agentes causales de micosis vaginal en mujeres sexualmente activas}

Vol. 2, núm. 1., (2018)

Irma Parrales Pincay; Cristobal Franco Quinde; William Lino Villacreses; María Chávez Rivadeneira

¿Con qué frecuencia asea su zona genital?

Cuadro y grafico \#2

\begin{tabular}{l|lll}
\multicolumn{1}{l}{ Variable } & frecuencia & Porcentajes \\
\hline 2 veces al dia & 16 & $53,33 \%$ \\
3 a 4 veces al dia & 9 & $30,00 \%$ \\
5 veces a dia & 5 & $16,67 \%$ & $53,33 \%$
\end{tabular}

La segunda interrogante hace énfasis en la frecuencia del aseo de la zona genital en la cual, el 53,33\% correspondiente a 16 mujeres que mencionaron que se asean solo dos veces al día, mientras que el 30,00\% correspondiente a 9 mujeres manifestó que se asean de tres a cuatro veces al día, por lo consiguiente el $16,67 \%$ correspondiente a 5 mujeres contestaron que se asean más de cinco veces en procesos de menstruación. 
Especies de Cándidas como agentes causales de micosis vaginal en mujeres sexualmente activas

Vol. 2, núm. 1., (2018)

Irma Parrales Pincay; Cristobal Franco Quinde; William Lino Villacreses; María Chávez

Rivadeneira

\section{¿Usted presenta alguno de los siguientes síntomas?}

\section{Cuadro y grafico \#3}

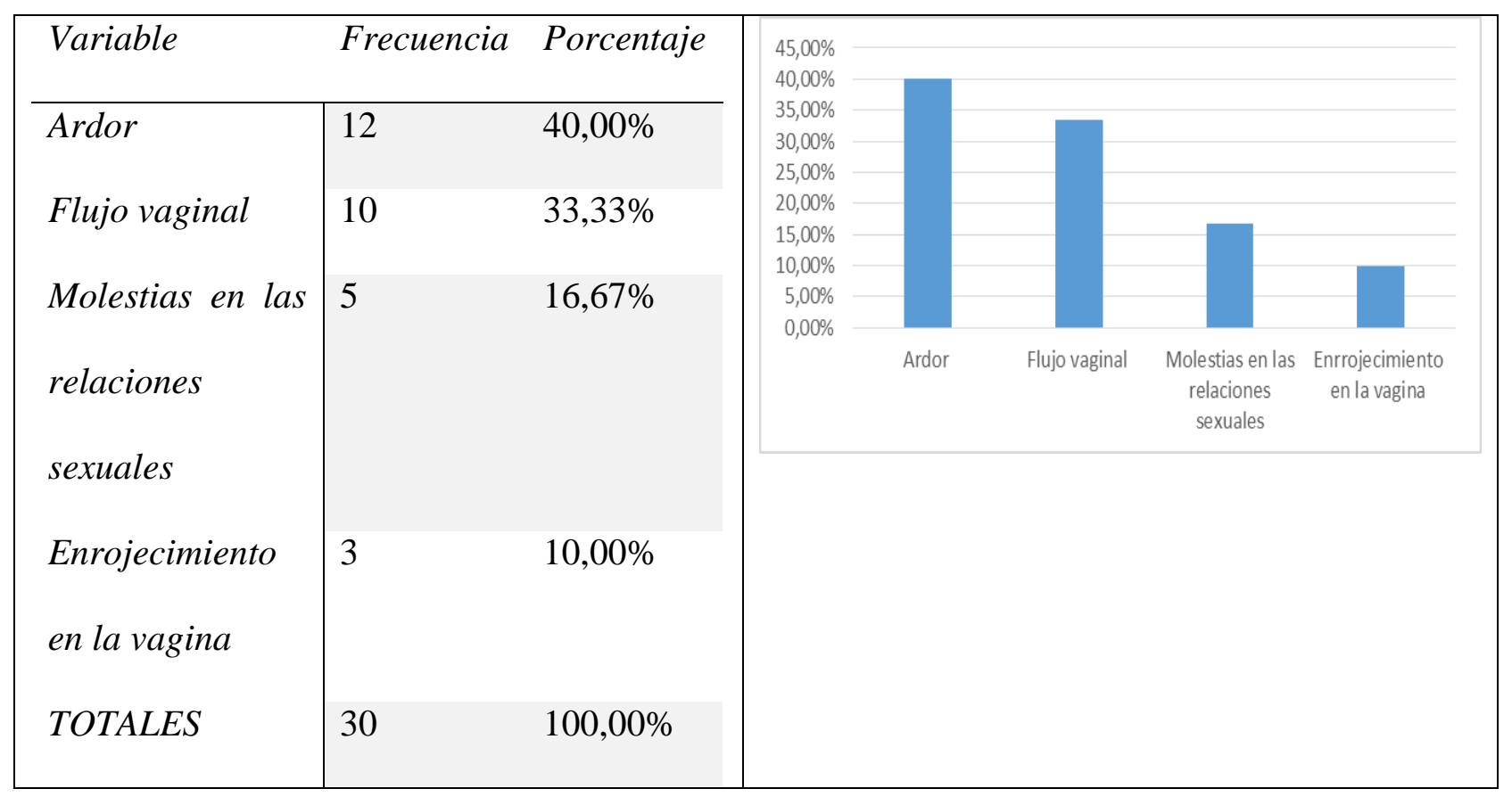

Al consultar sobre los síntomas comunes de una micosis vaginal el porcentaje más alto lo tuvo la presencia de ardor con el 40,00\% correspondiente a 12 mujeres, mientras el 33,33\% correspondiente a 10 mujeres que manifestaron presentar flujo vaginal, además el $16.67 \%$ corresponde a 5 mujeres indicaron tener molestias en las relaciones sexuales y por último el $10,00 \%$ corresponde a 3 mujeres contestaron que haber presentado enrojecimiento en la vagina. 


\section{Especies de Cándidas como agentes causales de micosis vaginal en mujeres sexualmente activas}

Vol. 2, núm. 1., (2018)

Irma Parrales Pincay; Cristobal Franco Quinde; William Lino Villacreses; María Chávez Rivadeneira

De acuerdo a los resultados obtenidos de los cultivos de muestras de secreción vaginal en Agar Sabouraud.

El primer ítem corresponde a los cultivos de las muestras de secreción vaginal en la cual, el $80,00 \%$ correspondiente a 24 casos positivos de crecimiento de formas micóticas, después de 24 horas en los medios de cultivo Agar Sabouraud, mientras que el 20,00\% correspondiente a 6 casos negativos, es decir, no hubo crecimiento de formas micóticas en los medios de cultivo Agar Sabouraud.

En conclusión, podemos decir que el $80 \%$; de las mujeres que son atendidas en el centro de salud Charapotó, padecen de micosis vaginal por especies de Cándidas.

\section{De acuerdo a los resultado de la identificación de especies de Cándidas en Agar Chromagar.}

En los 24 casos positivos de crecimiento de formas micóticas en Agar Sabouraud, se procedió a la siembra e identificación de las especies de cándidas mediante el Agar Chromagar dando como resultado la identificación de Cándida albicans en el 62,50\% equivalente a 15 casos; Cándida tropicalis con el 33,33\% correspondiente a 8 casos y Cándida krusei con el 4.17\% equivalente a 1 casos.

Se concluye, que el 62,50\% de las mujeres sexualmente activas presentan una infección micótica a causa de Cándida albicans siendo la especie de mayor predominio, por lo tanto el porcentaje restante corresponde a las dos especies; Cándida tropicalis con el 33,33\%, y Cándida krusei con el 4,17\%. 


\section{Especies de Cándidas como agentes causales de micosis vaginal en mujeres}

sexualmente activas

Vol. 2, núm. 1., (2018)

Irma Parrales Pincay; Cristobal Franco Quinde; William Lino Villacreses; María Chávez

Rivadeneira

\section{Discusión.}

El área genital femenina alberga diferentes tipos de bacterias. Estos organismos vivos protegen a la vagina de las bacterias y hongos que causan las infecciones, pero hay determinados factores que afectan a estas bacterias buenas y crean estragos en el sistema inmunológico de la vagina, fortaleciendo a los organismos malos, favoreciendo su multiplicación y la aparición de una infección vaginal por levaduras. (10)

Se sugiere que las infecciones recurrentes por Cándida afectan actualmente al 5\% de las mujeres en todo el mundo. No importa en qué lugar del mundo usted vive usted puede ser afectada por este problema que es cada vez mayor. La verdad es que irónicamente entre mayor es la cantidad de tratamientos disponibles para tratar el problema, mayores son las posibilidades de padecer infecciones crónicas por Cándida. (11)

Los cambios hormonales que se producen en el cuerpo femenino pueden provocar estragos, dejando como consecuencia algunos problemas indeseados, como la candidiasis vaginal. Y si bien es una infección habitual, debes saber que es provocada por la levadura Cándida, un tipo de hongo que produce los síntomas como dolor, picazón, enrojecimiento, flujo vaginal espeso de color blanco, molestias al orinar y mal olor. Sin embargo, para prevenir la aparición de esta molesta infección vaginal, debes tomar en cuenta lo siguiente. (12)

a) Mantener seca la zona vaginal: Los hongos suelen crecer en áreas húmedas y oscuras del cuerpo, por lo que resulta fundamental que a la hora de tomar un baño o luego de orinar, dejes lo más seca posible la vagina. 


\section{Especies de Cándidas como agentes causales de micosis vaginal en mujeres sexualmente activas}

Vol. 2, núm. 1., (2018)

Irma Parrales Pincay; Cristobal Franco Quinde; William Lino Villacreses; María Chávez Rivadeneira

b) Evita el uso de jabón: Pocas mujeres saben que los genitales deben ser lavados solamente con agua, pues el pH de la vagina se ve profundamente alterado al momento de utilizar jabón. Al alterarse el pH natural, dejas expuesto el organismo a la intervención de diferentes infecciones.

c) Tomar resguardos con el uso de antibióticos: Si bien, los médicos recetan este tipo de medicamentos para combatir o tratar una infección bacteriana, el cuerpo no sabe diferenciar entre aquellas que resultan nocivas, de las "beneficiosas", que se encargan de tener bajo control a las levaduras de la zona. Siempre consulta a tu médico acerca del consumo de prebióticos u otro tipo de alimento que ayude a reponer eficazmente el normal funcionamiento del organismo.

d) Mantén los niveles de azúcar bajo control: Las levaduras suelen proliferar cuando la concentración de azúcar en la sangre es elevada. Así que si presenta problema de diabetes, es hora de comenzar a ponerle control para no desarrollar hongos.

e) Escoger con cuidado la ropa interior: Optar siempre por prendas que sean de algodón, tejidos como el nylon retienen el calor y la humedad, favoreciendo el paso de las infecciones.

f) Cuidado al momento de tener relaciones sexuales: $\mathrm{Si}$ bien no se consideran una enfermedad de transmisión sexual, si pueden contagiarse al momento de tener relaciones sexuales. Así que si está sufriendo a causa de la candidiasis, es mejor consultar a tu doctor por el uso de preservativos (condones) antes de tener intimidad sexual con tu pareja. 


\section{Especies de Cándidas como agentes causales de micosis vaginal en mujeres}

sexualmente activas

Vol. 2, núm. 1., (2018)

Irma Parrales Pincay; Cristobal Franco Quinde; William Lino Villacreses; María Chávez

Rivadeneira

g) Procurar dejar atrás las prendas muy ceñidas al cuerpo: $\mathrm{Al}$ igual que la ropa interior de materiales diferentes al algodón, la ropa muy ajustada puede causar irritación. Evítala.

h) Las duchas vaginales: Éstas eliminan los mecanismos de defensa del cuerpo, dejándolo expuesto al desarrollo de hongos.

i) Evitar el uso de tampones: Procurar utilizar toallas higiénicas por sobre el tampón. Cambiar éstas con regularidad para intentar mantener los más seca posible tu zona íntima.

\section{Conclusión.}

Se fundamentó bibliográficamente sobre las especies de Cándidas y su relación con las alteraciones de la flora vaginal, mediante información procedente de artículos científicos, libros y revistas médicas que estructuraron las bases teóricas de la investigación.

Se establecieron los factores de riesgo que predisponen a una infección vaginal, dentro de los que sobresalen el uso de ropa íntima inadecuada con el 33,33\%, uso de jabón de tocador para asearse la vagina con un $26,67 \%$, las relaciones sexuales con varias parejas con el $23,33 \%$ y el uso continuo de protectores, toallas sanitarias, tampones, etc. Con un 16,67\%. Esto lleva a que las pacientes manifiesten el padecimiento de los síntomas comunes de una micosis vaginal el porcentaje más alto lo tuvo la presencia de ardor con el 40,00\% correspondiente, mientras el 33,33\% manifestaron presentar flujo vaginal, además el 16,67\% indicaron tener molestias en las relaciones sexuales y por último el $10,00 \%$ contestaron que haber presentado enrojecimiento en la vagina. 


\section{Especies de Cándidas como agentes causales de micosis vaginal en mujeres sexualmente activas}

Vol. 2, núm. 1., (2018)

Irma Parrales Pincay; Cristobal Franco Quinde; William Lino Villacreses; María Chávez Rivadeneira

De las 30 muestras de secreciones vaginales cultivadas en Agar Sabouraud hubo crecimiento de formas micóticas en el $80,00 \%$ de los casos correspondientes a 24 muestras, mientras que en el 20,00\% restante equivalente a 6 muestras no hubo crecimiento alguno. Dentro de las 24 muestras con crecimiento de formas micóticas en Agar Sabouraud, se procedió a identificar las especies de cándidas mediante el uso de Agar Chromagar dando como resultado C. albicans con un $62,50 \%$, C. tropicalis con el 33,33\% y C. krusei con un $4,17 \%$.

Según la hipótesis planteada "El 80\% de las mujeres atendidas en el Centro de Salud Charapotó padecen micosis vaginal por especies de cándidas” esta es aceptada debido a que los resultados obtenidos son positivos, según los rangos planteados.

\section{Bibliografía.}

1. Pineda-Murillo J, Cortés-Figueroa A, Uribarren-Berrueta T, Castañón-Olivares L. Candidosis vaginal. Revisión de la literatura y situación de México y otros países latinoamericanos. Revista Médica de Risaralda. 2017 Jun; 23(1): p. 38-44.

2. Calderone R, Clancy C. Candida and Candidiasis. 2nd ed. Washington: ASM Press; 2011.

3. Núñez-Velasco S, Jiménez-Cornejo M. Candidiasis. Hipoc Rev Med. 2011 Oct; 24(1): p. 1215.

4. Girard R, Perraud M, Prüss A, Savey A. Prevención de las infecciones nosocomiales GUÍA PRÁCTICA. 2nd ed. Ginebra: Organización Mundial de la Salud; 2003.

5. Chin J. El control de las enfermedades transmisibles Washington: OPS; 2001.

6. MSP. Perfil de morbilidad ambulatoria Quito: Ministerio de Salud Publica ; 2015.

7. Biasoli M. CANDIDIASIS Cordova: Universidad Nacional de Rosario; 2016.

8. Soriano Fernández H, Rodenas García L, Moreno Escribano D. Criterios de Elegibilidad de 


\section{Especies de Cándidas como agentes causales de micosis vaginal en mujeres}

sexualmente activas

Vol. 2, núm. 1., (2018)

Irma Parrales Pincay; Cristobal Franco Quinde; William Lino Villacreses; María Chávez

Rivadeneira

Métodos Anticonceptivos. Nuevas Recomendaciones. Revista Clínica de Medicina de Familia. 2010 Oct; 3(3): p. 206-216.

9. Miró M, Rodríguez E, Vigezzi C, Icely P. Candidiasis vulvovaginal: una antigua enfermedad con nuevos desafíos. Rev Iberoam Micol. 2017 Jul; 34(1): p. 65-71.

10. Ciudad-Reynaud A. INFECCIONES VAGINALES POR CÁNDIDA:DIAGNÓSTICO Y TRATAMIENTO. Revista Peruana de Ginecología y Obstetricia. 2007 Sep; 53(3): p. 159166.

11. Tapia C. Candidiasis vulvovaginal. Revista chilena de infectología. 2008 Ago; 25(4): p. 310312.

12. Cires Pujol M, Santiesteban EF, Silva Herrera L. Guía para la práctica clínica de las infecciones vaginales. Rev Cubana Farm. 2003 Sep; 37(1): p. 38-52. 